\title{
AS ABORDAGENS DEMOGRÁFICAS NA CONSOLIDAÇÃO DO PROCESSO ABOLICIONISTA BRASILEIRO
}

\author{
Marcelo Penna da Silva ${ }^{1}$ \\ Victor Pereira de Sousa ${ }^{2}$
}

\begin{abstract}
Resumo: O presente trabalho visa analisar os impactos demográficos no Brasil, no recorte temporal do período abolicionista (1850 - 1888), onde se analisará partir da Lei Eusébio de Queiroz (1850), cuja proibição efetiva do Tráfico negreiro incentivou a migração de cativos entre as regiões brasileiras - tráfico interprovincial, no qual se deslocavam para o principal ponto do Brasil, as regiões cafeeiras no sudeste brasileiro. Veremos que o incentivo à imigração baseada no processo de branqueamento demográfico foi a solução para dois problemas: o excedente populacional agrícola europeu e a mão de obra assalaria para a lavoura. Dessa forma, compreenderemos que o Brasil, movido pelo crescente mercado capitalista alicerçado no café, retoma o processo de imigração e, influenciado pela maior potência mundial do século $X I X$, a Inglaterra, consolida o processo abolicionista brasileiro, cujo estão intimamente relacionados à economia do Brasil no Segundo Reinado e a demografia.
\end{abstract}

Palavras-chave: Demografia; Abolição; Imigração. 1 Graduando em Geografia/Universidade do Estado do Rio de Janeiro - UERJ, Brasil. E-mail:
celo_penna2@hotmail.com
2 Graduando em Geografia/Universidade do Estado do Rio de Janeiro - UERJ, Brasil. E-mail:
victordesousa@outlook.com.br 